\title{
Giant saccular aneurysm of the distal A2 segment of the azygos anterior cerebral artery. Difficulties in surgery
}

\section{Tętniak gigant pojedynczego pnia tętniczego segmentu A2 tętnicy przedniej mózgu. Trudności w postępowaniu chirurgicznym}

\author{
Jarosław Andrychowski
}

Department of Neurology, Neurological Rehabilitation and Kinesitherapy, Collegium Medicum, University Jan Kochanowski, Kielce, Poland Head of the Department: Prof. JKU Piotr Sobolewski MD, PhD

Azygos artery (a. azygos) in the anterior cerebral artery A2 segment is a rare anatomic anomaly, as well as giant saccular aneurysm in the A2 segment of the a. azygos trunk. Giant aneurysm of the azygos A2 segment artery is incidental, and thus far literature has reported only a small number of cases, treated surgically after the subarachnoid haemorrhage.

The literature also provides a description of the coexistence of an azygos artery with corpus callosum hypoplasia, porencephalia, or vascular malformation [1-4]. In my own extensive (material subsequently treated by clipping and reviewed patients after subarachnoid haemorrhage within the last 10 years, no case of an azygos anterior artery A2 segment and coexisting giant aneurysm has been found. Differentiating the anatomic type between azygos artery and paired vascular system based on brain arteriography after subarachnoid haemorrhage is difficult due to the asymmetry of paired vessels, uneven contrast enhancement, and the possibility of vasospasm after subarachnoid haemorrhage. Angiography may suggest anomaly. Final verification is possible during the surgical approach and exposure of the vessels during the preparation of the main vessel in longitudinal fissure of the brain. I encountered this problem during my clinical practice.

Initially, computed tomography (CT) examination revealed a pathological mass in the longitudinal fissure and blood collection in the regional subarachnoid space. Angiography revealed a giant aneurysm of the A2 segment located slightly above the genu of corpus callosum, and this triggered speculation as to the type of pericallosal artery anomaly, e.g. high division of pericallosal arteries, azygos artery, left pericallosal artery hypoplasia, or spasm of the vessel (Figures 1,2). It was an urgent clinical situation on surgical duty. After angiography we discussed firstly about embolisation of the aneurysm because we have good cooperation with my colleagues from radiology. Finally, we decided to perform surgery because the aneurysm was giant with a wide neck, and it was

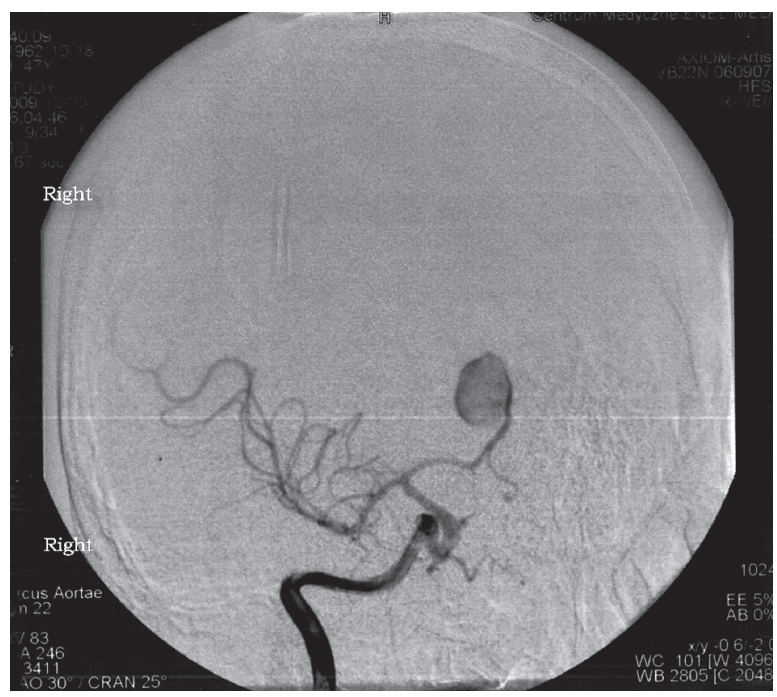

Figure 1 . Angiography examination of giant aneurysm before operation

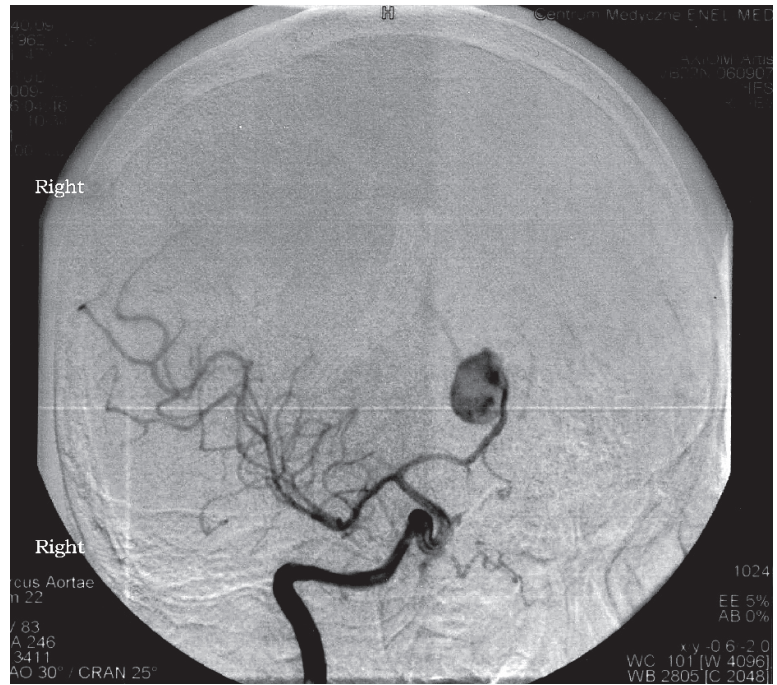

Figure 2. Angiography examination of giant aneurysm before operation - A2 azygos trunk 


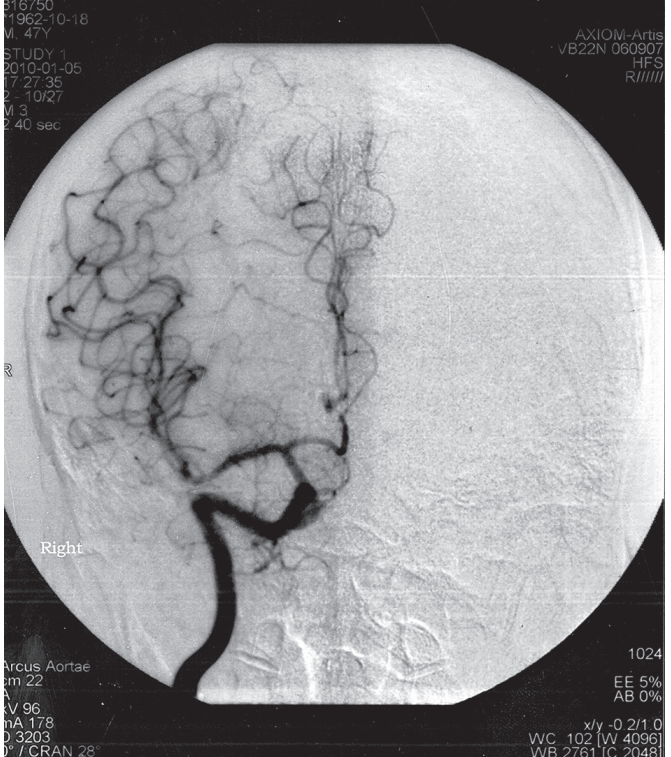

Figure 3. The control angiography after clipping - anterior view

located on a single vascular trunk with suspicion of thrombus inside the aneurysm sac. We were afraid of rapid recanalisation of the giant aneurysm sac after the coiling procedure.

I performed the surgery using the interhemispheric approach, preparing the longitudinal fissure from the base. The bottom of the fissure and the surface of the corpus callosum were reached, where a single trunk - azygos pericallosal artery was identified, divided into three branches on the level of the genu of the corpus callosum. A giant aneurysm was found in the vessel extension, described intraoperatively as a truncated cone, with the apex directed towards the azygos A2 segment artery, two vessels running towards the medial part of the frontal lobe, and the a. azygos trunk along the corpus callosum, divided approx. 10-12 mm behind the wide aneurysm neck. The aneurysm sac was not susceptible to clipping due to thick walls and suspicion of thrombus inside; the clips slid down and closed the vessel. Clipping the aneurysm without temporary clips proved impossible. The aneurysm was clipped using the temporary occlusion of the azygos artery trunk for approx. 20-30 s. In the meantime, the aneurysm sack was drained by puncturing and aspirating with a very thin needle; the wide aneurysm neck was clipped, preserving the lumen of the arterial trunk. Despite proximal application of two parallel bayonet-shaped titanium clips, the aneurysm sack continued to fill with blood. The arms of the clips covered the span of the aneurysm neck. It was established that the clipping manoeuvre was insufficient. The azygos artery

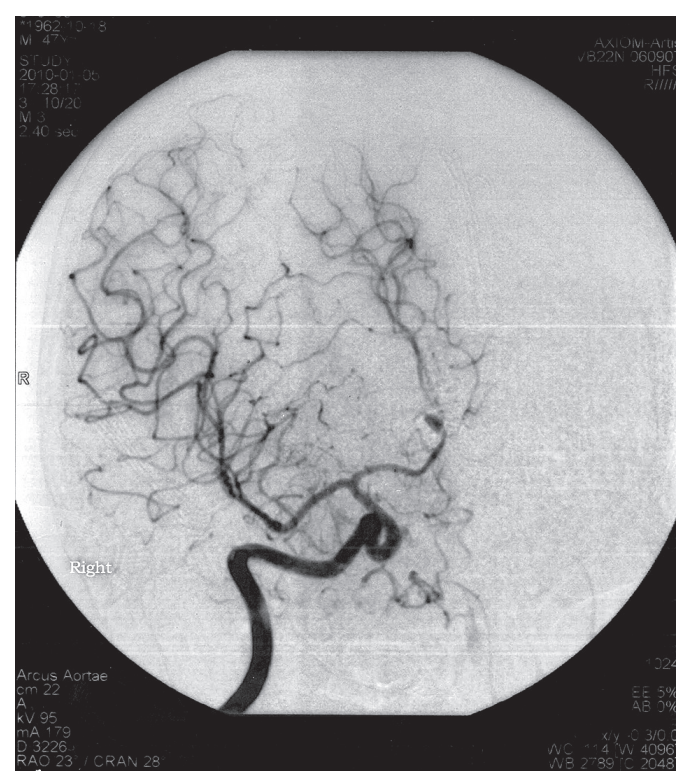

Figure 4. The control angiography after clipping - oblique view

trunk was occluded twice more for approx. 20-30 s, each time changing the location of the temporary clip on the main vessel. The aneurysm was drained of residual blood by puncturing, in order to reduce the wall tension, and further clips were attached to the aneurysm sack. In the final stage the distal part of the aneurysm sack was ruptured, and blood was drained, along with the thrombus. Six clips, located proximally on the neck, were clamped mechanically by an additional, larger clip. It was established intraoperatively that the giant aneurysm walls were hard and featured low susceptibility to clipping. Therefore, I decided not to perforate the aneurysm sack, and removed the blood during temporary occlusion instead; the clipping of the sack was adjusted using six parallel clips and an additional clamp clip. Postoperative course was very good. A control angiography was performed (Figures 3-5). Azygos artery A2 segment was suspected in vascular examinations before surgery and was confirmed during interhemispheric surgical approach. Potential diagnostic difficulties and misinterpretation may arise due to post-haemorrhage vasospasm(s), or domination one of anterior cerebral artery on the one side or anterior cerebral artery hypoplasia from other.

Incorrect diagnosis might also be caused by using an improper angiography technique and absence of cross-filling technique when assessing the anterior communicating artery complex $[5,6]$.

In our materials from the last 10 years we have assessed 800 patients, diagnosed and subjected to surgical treatment by clipping of an aneurysm after 
subarachnoid haemorrhage. This was the only case of a giant aneurysm located in the azygos pericallosal artery. In the literature of the subject only a handful of cases have been reported on the location and surgical treatment of giant aneurysm in azygos pericallosal artery [4, 6-10].

Publications concerning the surgical treatment in particular highlight the possibility of partial thrombosis within the area of the aneurysm sack and the related disproportion in the assessment of sack dimensions; therefore, the vascular imaging examination should be supplemented with CT and magnetic resonance imaging (MRI) [5, 10, 11]. Aneurysm - inside sack - thrombosis and the suggestion of thick walls pose specific difficulties for surgical procedure due to the low susceptibility of the sack to the pressure of the clip branches and sliding of the branches from the neck, which leads to the risk of occlusion of the parent vessel. The specified diagnostic procedure refers to all giant aneurysms with different cerebral locations, especially when the surgeon uses the technic of cardiac pacing intraoperatively and when the surgeon has no cerebral arterial bypass skills.

We appreciate the collaboration with our endovascular colleagues, but on neurosurgical duty we had less time for discussion when the patient was suffering from subarachnoid bleeding. We had disappointing experiences with the recanalisation of giant aneurysms after coiling, and we discussed this problem in our department, published the results, and they was compared with the existing literature $[1,12,13]$. Management of aneurysm of azygos ACA is by surgical clipping or by endovascular coiling. Most published cases on this topic have been managed by surgical clipping [4, 6-8, 10, 11, 14, 15]. Endovascular coiling of an azygos ACA aneurysm has been reported in a few cases [16]. Surgical treatment of a giant aneurysm located in the azygos pericallosal artery after subarachnoid haemorrhage is a major challenge [3, 5-8, 12, 14]. Surgical exclusion of a giant aneurysm of any artery location is always more problematic in technical terms (problems related to using temporary clips, thick wall of the aneurysm sac, anatomical shape, and blood clots inside). The azygos A2 trunk is a special situation in which a large brain region is vascularised by the simple trunk of the artery, and this vessel has a specific anatomic characteristic. The problem of potential consequences of postoperative ischaemia becomes more prominent. It is known that attaching a temporary clip may lead to a risk of neurological deficit, caused by a spasm or changes in the endothelium of the vessels. Therefore, the timing of temporary clipping of the vessel is crucial.

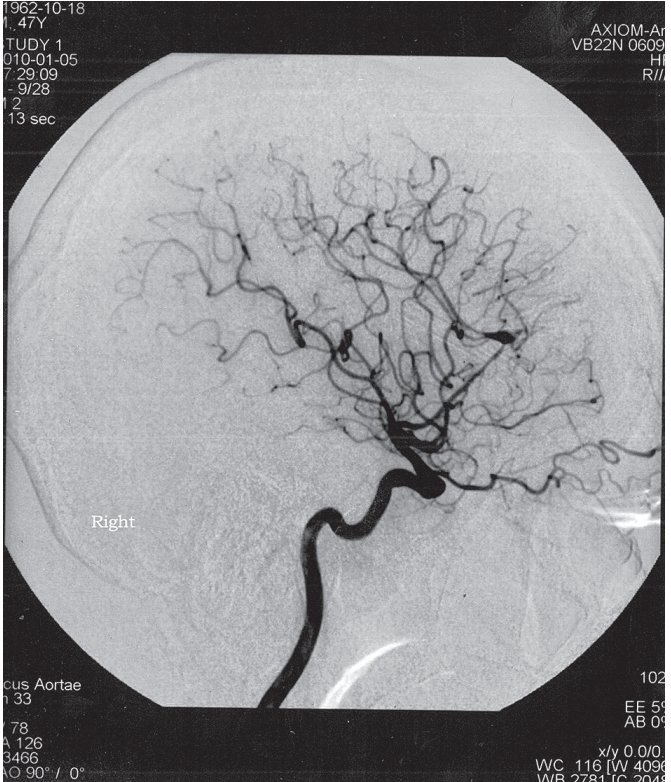

Figure 5. The control angiography after clipping - lateral view

\section{Conflict of interest}

The author declares no conflict of interest.

\section{References}

1. Andrychowski J. Embolitic material (coils) dislocation inside a giant and cerebral aneurysm and morphological aneurysm changes after coiling. Case report. Neurol Neurochir Pol 2001; 35: 1149-1160.

2. Baptista AG. Studies on the arteries of the brain I. The anterior cerebral artery. Some anatomic features and their clinical implications. Neurology 1963; 13: 825-835.

3. Baykal S, Ceylan S, Dinc H, Soylev E, Usul H, Akturk F. Aneurysm of an azygos anterior cerebral artery: report of two cases and review of the literature. Neurosurgic Rev 1996; 19: 57-59.

4. Baldawa S, Katikar D, Marda S. Giant saccular distal azygos artery aneurysm: report of a case and review of literature. Asian J Neurosurg 2016; 11: 175.

5. Cinnamon J, Zito J, Chalif DJ, Gorey MT, Black KS, Scuderi DM, Hyman RA. Aneurysm of the azygos pericallosal artery: diagnosis by MR imaging and MR angiography. Am J Neuroradiol 1992; 13: 280-282.

6. Hashizume K, Nukui H, Horikoshi T, Kaneko M, Fukamachi A. Giant aneurysm of the azygos anterior cerebral artery associated with acute subdural hematoma - case report. Neurol Med Chir 1992; 32: 693-697.

7. Hayashi M, Kobayashi H, Kawano H, Handa Y, Kabuto M. Giant aneurysm of an azygos anterior cerebral artery: report of two cases and review of the literature. Neurosurgery 1985; 17: 341-344

8. Kanemoto Y, Tanaka Y, Nonaka M, Hironaka Y. Giant aneurysm of the azygos anterior cerebral artery - case report. Neurol Med Chir 2000; 40: 472-475. 
9. Kashiwazaki D, Kuroda S, Horiuchi N, Takahashi A, Asano T, Ishikawa T, Iwasaki Y. Ruptured aneurysm of bihemispheric anterior cerebral artery bifurcation: case report. No Shinkei Geka 2005; 33: 383-387.

10. Mishima K, Watanabe T, Sasaki T, Saito I, Takakura K. An infected partially trombosed giant aneurysm of the azygos anterior cerebral artery. No Shinkei Geka 1990; 18: $475-481$

11. Topsakal C, Ozveren MF, Erol FS, Cihangiroglu M. Giant aneurysm of the azygos pericallosal artery: case report and review of the literature. Surg Neurol 2003; 60: 524-533.

12. Graziano F, Iacopino DG, Ulm AJ. Insights on a giant aneurysm treated endovascularly. J Neurol Surg A Cent Eur Neurosurg 2016; 77: 367-371.

13. Wang B, Gao BL, Xu GP, Xiang C, Liu XS. Endovascular embolization is applicable for large and giant intracranial aneurysms: experience in one center with long-term angiographic follow-up. Acta Radiol 2015; 56: 105-113.

14. Ghanta RK, Kesanakurthy MV, Vemuri VN. Aneurysm of azygos anterior cerebral artery: a report of two cases. Asian J Neurosurg 2016; 11: 312.

15. Seferi A, Alimehmeti R, Rroji A, Petrela M. Saccular trilobedaneurysm of azygos anterior cerebral artery. World J Clin Cases 2015; 3: 377-380.

16. Sarikaya B, Oksuz E, Deniz FE, Firat MM. Endovascular treatment of a ruptured aneurysm at a very rare location. Distal azygos anterior cerebral artery. Interv Neuroradiol 2008; 14: 457-460.

\section{Address for correspondence:}

Prof. Jarosław Andrychowski MD, PhD, DSc

Department of Neurology, Neurological Rehabilitation, and Kinesitherapy

Collegium Medicum

Jan Kochanowski University

ul. Żeromskiego 5, 25-369 Kielce, Poland

Phone: +48 501121757

E-mail: j.andrychowski@wp.pl 